\title{
$\begin{array}{r}\text { WAGENINGEN } \\ \hline \\ \hline\end{array}$
}

Time-dependent ion selectivity in capacitive charging of porous electrodes

Zhao, R., Soestbergen, M., Rijnaarts, H. H. M., van der Wal, A. F., Bazant, M. Z., \& Biesheuvel, P. M.

This is a "Post-Print" accepted manuscript, which has been published in "Journal of Colloid and Interface Science"

This version is distributed under a non-commercial no derivatives Creative Commons

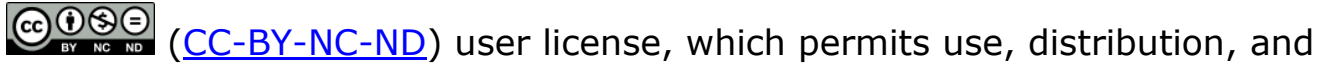
reproduction in any medium, provided the original work is properly cited and not used for commercial purposes. Further, the restriction applies that if you remix, transform, or build upon the material, you may not distribute the modified material.

Please cite this publication as follows:

Zhao, R., Soestbergen, M., Rijnaarts, H. H. M., van der Wal, A. F., Bazant, M. Z., \& Biesheuvel, P. M. (2012). Time-dependent ion selectivity in capacitive charging of porous electrodes. Journal of Colloid and Interface Science, 384(1), 38-44.

https://doi.org/10.1016/j.jcis.2012.06.022 


\section{Time-dependent ion selectivity in capacitive charging of porous electrodes}

R. Zhao, ${ }^{1,2}$ M. van Soestbergen, ${ }^{2,3}$ H.H.M. Rijnaarts, ${ }^{1}$

A. van der Wal, ${ }^{1,4}$ M.Z. Bazant ${ }^{5}$ and P.M. Biesheuvel ${ }^{1,2, *}$

${ }^{1}$ Department of Environmental Technology, Wageningen University, Bornse Weilanden 9, 6708 WG

Wageningen, The Netherlands. ${ }^{2}$ Wetsus, centre of excellence for sustainable water technology, Agora 1, 8934 CJ Leeuwarden, The Netherlands. ${ }^{3}$ Department of Applied Physics, Eindhoven University of Technology, Den Dolech 2, 5612 AZ Eindhoven, the Netherlands. ${ }^{4}$ Voltea B. V., Wasbeekerlaan 24, 2171 AE Sassenheim, the Netherlands. ${ }^{5}$ Department of Chemical Engineering and Department of Mathematics, Massachusetts Institute of Technology, Cambridge, MA 02139, USA.

E-mail: maarten.biesheuvel@wur.nl.

Full corresponde details corresponding author: Dr. P.M. Biesheuvel. Department of Environmental Technology, Wageningen University, Bornse Weilanden 9, 6708 WG Wageningen, The Netherlands. E-mail: maarten.biesheuvel@wur.nl. Tel. +0031646193949.

\section{Abstract}

In a combined experimental and theoretical study we show that capacitive charging of porous electrodes in multicomponent electrolytes may lead to the phenomenon of time-dependent ion selectivity of the electrical double layers (EDLs) in the electrodes. This effect is found in experiments on capacitive deionization of water containing $\mathrm{NaCl} / \mathrm{CaCl}_{2}$ mixtures, when the concentration of $\mathrm{Na}^{+}$ ions in the water is 5 times higher than the $\mathrm{Ca}^{2+}$-ion concentration. In this experiment, after applying a voltage difference between two porous carbon electrodes, first the majority monovalent $\mathrm{Na}^{+}$cations are preferentially adsorbed in the EDLs, and later they are gradually replaced by the minority, divalent $\mathrm{Ca}^{2+}$ cations. In a process where this ion adsorption step is followed by washing the electrode with freshwater under open-circuit conditions, and subsequent release of the ions while the cell is shortcircuited, a product stream is obtained which is significantly enriched in divalent ions. Repeating this process three times by taking the product concentrations of one run as the feed concentrations for the next, a final increase in the $\mathrm{Ca}^{2+} / \mathrm{Na}^{+}$-ratio of a factor of 300 is achieved. The phenomenon of timedependent ion selectivity of EDLs cannot be explained by linear response theory. Therefore, a nonlinear time-dependent analysis of capacitive charging is performed for both porous and flat electrodes. Both models attribute time-dependent ion selectivity to the interplay of the transport resistance for the ions in the aqueous solution outside the EDL, and the voltage-dependent ion adsorption capacity of the EDLs. Exact analytical expressions are presented for the excess ion adsorption in planar EDLs (Gouy-Chapman theory) for mixtures containing both monovalent and divalent cations.

key-words: water desalination; porous electrode theory; capacitive (non-faradaic) electrochemical cells; electrostatic double layer theory. 


\section{Introduction}

Over the coming decades an increasing part of the world population will face the effects of shortages in freshwater if present trends in population growth and economic development continue [1-7]. When seawater or brackish ground water are available as sources of freshwater, energy-efficient desalination can be a strategy to relieve water scarcity. In commercial desalination technologies, such as reverse osmosis and multistage flash distillation, freshwater is produced at relatively high energy cost and often requires re-mineralization for human consumption. For brackish water or wastewater it can be advantageous to use a different type of technology, namely techniques where ions are removed from the feed water under the influence of electrical field effects, such as in electrodialysis [8,9], capacitive deionization [10-28], membrane capacitive deionization [29-34], desalination using microchannels [35], batteries [36], microbial desalination cells [37] and wires [38]. Such techniques have the potential to be energy-efficient as they focus on the removal of the (often relatively few) ions in the water to obtain freshwater in this way. Also, they should have the potential to treat water in an ion-selective manner, i.e., to specifically remove undesired ions (e.g., poisonous metal ions like arsenic, or radionuclides, or ions involved in scaling/fouling), while keeping the composition of the water otherwise unchanged. Another potential option is to use such techniques to selectively harvest valuable ions from industrial water or seawater, such as lithium or lanthanide ions from seawater, which are of economical importance for the construction of batteries and other portable high-tech electronic devices [39]. All of these possibilities can contribute to the economic feasibility of the treatment of water for various objectives.

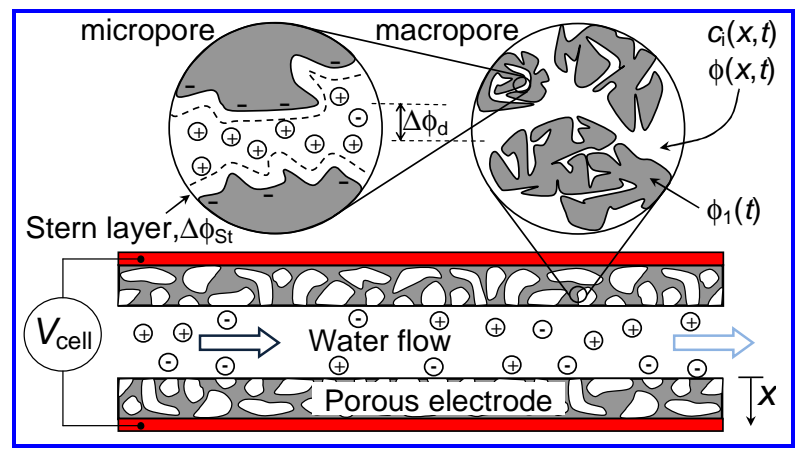

Fig. 1. Schematic view of a Capacitive Deionization (CDI) cell where ions are removed from the water flowing through a microchannel under the influence of an applied voltage difference $V_{\text {cell }}$ between two porous electrodes. The ions are temporarily stored in the micropores inside the carbon particles, which are the main constituent of the electrodes.

In this work we demonstrate, both theoretically and experimentally, the possibility of selective ion removal by one of the above techniques, namely capacitive deionization (CDI). To remove ions from water, in CDI an electrical potential difference, or cell voltage, is applied between two porous electrodes placed on either side of a microchannel that passes water, see Fig. 1. Due to the applied electric field, ions are removed from the water and are temporarily stored in the electrical double layers (EDLs) that form inside the micropores of the (typically carbon) particles, which are the major constituent of the porous electrodes. CDI has many similarities with supercapacitor battery technology $[5,40,41]$, though (i) the electrolyte is water (mainly organic electrolytes are used in supercapacitors), (ii) the ionic strength of the electrolyte is much lower (in supercapacitors of the order of $1 \mathrm{M}$ ), and (iii) 
the cell operates in a throughflow mode (whereas for supercapacitors the cell is closed off), while (iv) the objective is to remove ions (and storing charge is the objective for supercapacitors).

Theoretical and experimental studies of the structure of the EDL suggest that charged interfaces can have different excess adsorptions for different types of ions, in particular depending on their valency, and thus there is scope for the use of EDL-effects to treat water selectively [14,42-47]. Interestingly, the literature on CDI using mixtures of ions presents apparently contradictory results for the preference of the system to either adsorb monovalent ions, or divalent ions. Enhanced divalent ion adsorption has been reported [10,13,18], enhanced monovalent ion adsorption [12], as well as the absence of a clear preference in either direction [14].

Triggered by these contradictory findings, we systematically investigated the behavior of CDI in multicomponent electrolytes, both experimentally and theoretically. A key result of our study is that a subtle time dependence of ion selectivity of the EDLs is possible, and this effect can help to explain some of the above-described differences. What our data show is that it is possible that monovalent ions are preferentially adsorbed at first and are then gradually displaced again by divalent ions. We also present results of a three-step process that exploits the preference of the EDLs for divalent ions (after sufficient adsorption time), to obtain a product solution enriched in these divalent ions.

In the following sections, we first explain why standard linear EDL theory does not suffice to rationalize the phenomenon of time-dependent ion-selectivity of EDLs, and we continue with a brief description of our experimental setup. Equilibrium salt adsorption experiments are discussed next and are fitted with a modified Donnan model that will be presented. Subsequently, we present results of our dynamic experiments, which we compare qualitatively with time-dependent non-linear theory, both for planar electrodes and for porous electrodes, considering in all cases electrolytes that contain mixtures of both monovalent and divalent cations. The planar electrode model is based on exact analytical solutions for the individual excess ion adsorption capacities of a planar EDL (GouyChapman theory), which to the best of our knowledge have not yet been published before.

\section{Physical Mechanism of Time-dependent lon Selectivity}

Let us begin by noting the general failure of Debye-Hückel linear response theory in a first order approach for ion adsorption based on the diffuse layer concept, to predict the proposed effect of timedependent ion-selectivity. Linear response theory is based on linearizing the Boltzmann distribution of ion concentrations $c_{\mathrm{i}}$ for small potentials, i.e., $c_{\mathrm{i}}=c_{\mathrm{i}}^{\infty} \exp \left(-z_{i} \phi\right) \sim c_{\mathrm{i}}^{\infty}\left(1-z_{\mathrm{i}} \phi\right)$, where $c_{\mathrm{i}}^{\infty}$ is the ion concentration outside the EDL, $z_{\mathrm{i}}$ the ion charge number and $\phi$ the dimensionless electrical potential

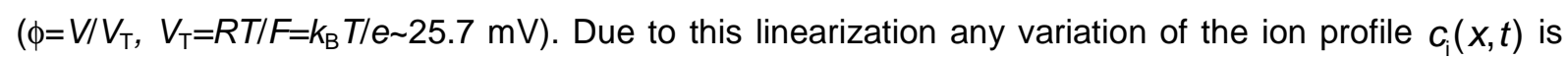
proportional to the local potential $\phi(x, t)$, which in turn is proportional to the applied voltage during "RC" charging dynamics $[48,49]$. In particular, the ratio of excess adsorption of species $i$ to species $j$ in the EDLs remains constant for all time, equal to $z_{i} C_{i}^{\infty} / z_{j} C_{j}^{\infty}$. Time-dependent ion selectivity is thus an inherently nonlinear effect.

In response to a large voltage $(|\phi|>>1)$, it is now well understood how EDLs adsorb net salt from a neutral bulk solution $[48,49,50]$ (the basis for CDI), but here we point out that individual ions adsorb 
preferentially at different times. For both flat [48,50] and porous electrodes [49,51], if the diffusecharge regions are "thin" compared to the electrode separation, they will remain in quasi-equilibrium during the charging dynamics (except during strong salt depletion at very large voltages [48,50]). As long as dilute-solution theory holds [43,52], the local ratio of ion concentrations in the EDLs is then given by $c_{\mathrm{i}} / c_{\mathrm{j}}=c^{\infty}{ }_{\mathrm{i}} / c^{\infty}{ }_{\mathrm{j}} \exp \left(\left(z_{\mathrm{j}}-z_{\mathrm{i}}\right) \phi\right)$. This simple argument implies a transient shift in ion adsorption as a large applied voltage is transferred from the bulk to the EDLs: at early times $(|\phi|<<1)$, the majority species with $c_{i}^{\infty}>c_{j}^{\infty}$ adsorbs preferentially, while at late times $(|\phi|>>1)$ these ions are replaced by those of greater valence $z_{\mathrm{j}}>z_{\mathrm{i}}$, even if they are the minority species in the bulk solution. A detailed theory for multicomponent electrolytes is presented below, but first we demonstrate this phenomenon experimentally for divalent $\mathrm{Ca}^{2+}$ ions in a supporting electrolyte with monovalent $\mathrm{Na}^{+}$ ions.

\section{Experimental Section}

For our experiments we use a setup that contains a "stack" of $8 \mathrm{CDI}$ cells, each consisting of a channel formed of a sheet of an open-meshed woven material (Glass fiber prefilter, cat no. AP2029325, Millipore, Ireland; compressed thickness $250 \mu \mathrm{m}$ ), with square porous activated carbon electrodes on each side (Materials \& Methods, PACMM ${ }^{\mathrm{TM}}$ 203, Irvine, CA, thickness $270 \mu \mathrm{m}$, outer dimensions $\left.6 \times 6 \mathrm{~cm}^{2}\right)[19,34,53]$. Dense electron-conducting sheets of graphite foil are in contact with the backside of each porous electrode. The electron-conducting sheets separate each cell from the next and allow for charge injection. A de-aired salt solution flows radially outward from the center of the cells (via a $1.5 \times 1.5 \mathrm{~cm}^{2}$ hole) through the square channels into a reservoir surrounding the stack (water flowrate $7.5 \mathrm{~mL} / \mathrm{min}$ per cell). Assuming a $50 \%$ porosity of the spacer channel, this implies a water residence time in the spacer channel of $\sim 3.4 \mathrm{~s}$. The conductivity of the effluent of the reservoir is measured on-line and is recalculated to salt concentration using a calibration curve. This procedure can only be used for single-salt solutions, not for mixtures. Instead, for our experiments with mixtures, we take samples at different times from the water flowing out of the stack (the effluent), and measure their ion concentrations off-line by inductively coupled plasma optical emission spectrometry (ICPOES), on two different instruments.

\section{Equilibrium Adsorption Experiments}

Before discussing the time-dependent CDI process, let us first present results for equilibrium ion adsorption and charge storage in CDI-cells consisting of two parallel porous electrodes. The results presented here extend our reports on ion adsorption in porous carbon electrodes in 1:1 monovalent salt solutions $[17,19,34]$. In such experiments a constant flow of water with predetermined salt concentration is continuously fed to the cell. At time zero the cell voltage, being the DC voltage applied between the two porous electrodes, $V_{\text {cell }}$, see Fig. 1 , is increased step-wise to the final value (chronoamperometry), and water desalination starts. For single-salt solutions, measurement of the effluent conductivity as function of time suffices to determine the total salt adsorption in the pair of electrodes. To calculate salt adsorption, the time-dependent value of the effluent salt concentration 
minus the inflowing concentration is integrated with time, multiplied by the water flow rate, and divided by the total electrode mass, to give the salt adsorption $\Gamma$ per gram of total electrode mass, as reported in Fig. 2a. The current is also measured, and integrated over time, to give the total electrode charge $q$, see Fig. 2b. The electrical charge in one electrode is the same in magnitude (but opposite in sign) as that in the other electrode. The adsorption experiment is continued until the effluent salt concentration is equal again to that of the inlet, for which $\sim 1 \mathrm{hr}$ is more than sufficient to reach equilibrium for singlesalt solutions [19,34].

Fig. $2 a$ and $2 b$ shows results for the equilibrium adsorption of $\mathrm{CaCl}_{2}$ in porous electrode pairs. As expected we find that salt adsorption and charge increase with cell voltage. For the two inflow salt concentrations (5 mM and $20 \mathrm{mM}$ ), we observe that we have slightly less salt adsorption at higher ionic strength but somewhat more charge stored, i.e., the charge efficiency (equilibrium salt adsorption divided by equilibrium charge) drops with increasing ionic strength, similar to what was reported previously for monovalent salt solutions [19]. Theoretical predictions by an EDL-model developed for porous electrodes, which we call the modified-Donnan $(\mathrm{mD})$ model, and which we will discuss in more detail further on, fit the data reasonably well, using as the parameter settings: $C_{\mathrm{St}, \mathrm{vol}}=120 \mathrm{MF} / \mathrm{m}^{3}$, $\alpha=35 \mathrm{~F} \cdot \mathrm{m}^{3} / \mathrm{mol}^{2}, p_{\mathrm{mi}}=0.36, p_{\mathrm{mA}}=0.30$, and $\rho_{\mathrm{e}}=0.55 \mathrm{~g} / \mathrm{ml}$. These values are estimated $\left(p_{\mathrm{mA}}\right)$, measured $\left(\rho_{\mathrm{e}}\right)$, or are fitted to the data $\left(C_{\mathrm{St}, \mathrm{vol}}, \alpha, p_{\mathrm{mi}}\right)$. Though fitted, they are realistic and similar to values used in previous work using the $\mathrm{mD}$ model. To simplify matters, we do not make use of the parameter $\mu_{\text {att }}$ in the present work, a parameter that we have used in the mD-model in refs. [23,25,34,51,54]. The relatively good fit of the $\mathrm{mD}$ model to the data, as shown in Fig. $2 a$ and $2 \mathrm{~b}$, shows that the $\mathrm{mD}$-model is a useful method to describe (summarize) data in a simple mathematical framework, simultaneously for salt adsorption and for charge, as function of ionic strength and as function of cell voltage. As we show in ref. 25 it can also be used for asymmetric electrode pairs, where one electrode has $2 x$ or $3 x$ the mass of the other electrode.

Next let us investigate the use of this mD-model to describe data for the adsorption behavior in mixtures of salts, as presented in Fig. 2c. Here we analyze adsorption from a mixture of $5 \mathrm{mM} \mathrm{NaCl}$ and $1 \mathrm{mM} \mathrm{CaCl}$, being the same water composition as will also be considered in the dynamic experiments to be discussed further on. Note that Fig $2 \mathrm{c}$ shows adsorption data for the salt mixture for different durations of the adsorption step, namely $1 \mathrm{hr}$ and $5 \mathrm{hr}$. Contrary to the single-salt experiments described above, an experimental duration of $1 \mathrm{hr}$ turned out to be insufficient to reach equilibrium, so the experiment was extended to $5 \mathrm{hr}$, when the individual ion adsorptions reach values consistent with the fitted equilibrium theory, see Fig. 2c. We assume that after $5 \mathrm{hr}$ we have reached adsorption levels that are close to equilibrium. Data in Fig. $2 \mathrm{c}$ are not obtained by collecting samples during the $5 \mathrm{hr}$ adsorption step; Instead, the adsorbed amount is calculated from collected samples during the desorption phase, which requires even less than $1 \mathrm{hr}$, as can be inferred from Fig. 3a.

In Fig. 2, lines present results of the mD-model, and as can be observed we can relatively well fit the data for mixtures using the same parameter settings that also describe data for pure $\mathrm{CaCl}_{2}$-solutions (panels $a, b$ ). This good fit suggests that the mD-model is a useful tool to describe experimental data for the equilibrium structure of the EDL in porous electrodes in contact with mixtures of salt. Because 
of its mathematical tractability the $\mathrm{mD}$-approach is very suitable to be included in a full dynamic porous electrode transport theory $[49,51,54]$.
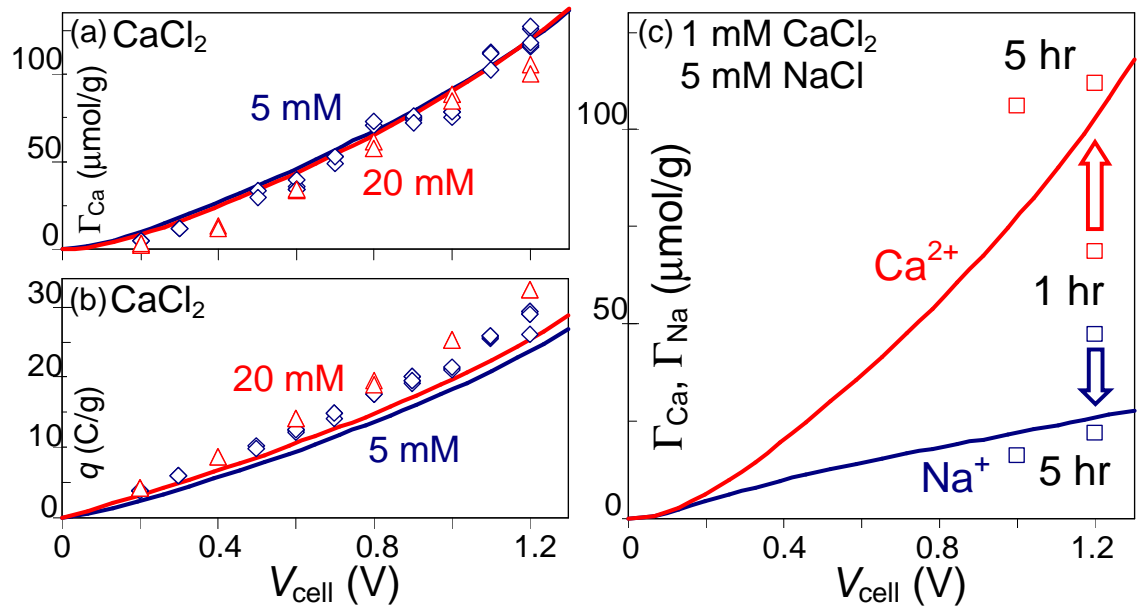

Fig. 2. (a,b). Equilibrium ion adsorption and charge as function of cell voltage $V_{\text {cell }}$ in $\mathrm{CaCl}_{2}$ mixtures at two values of the $\mathrm{CaCl}_{2}$-concentration (blue diamonds: $5 \mathrm{mM}$; red triangles: $20 \mathrm{mM}$ ). (c). Individual excess cation adsorption by a pair of porous electrodes, as function of $V_{\text {cell }}$, for one value of the $\mathrm{NaCl} / \mathrm{CaCl}_{2}$ mixing composition. Comparison of data (symbols) with modified-Donnan EDL-theory (lines).

\section{Dynamic Experiments}

The dynamic behavior of the $\mathrm{CDI}$ process for a $5 \mathrm{mM} \mathrm{NaCl} / 1 \mathrm{mM} \mathrm{CaCl}$-mixture is presented in Fig. 3a, showing the development of the effluent ion concentrations in time, after applying a cell voltage of $V_{\text {cell }}=1.2 \mathrm{~V}$ for $1 \mathrm{hr}$, and during subsequent ion desorption at $V_{\text {cell }}=0 \mathrm{~V}$. We chose for an adsorption time of $1 \mathrm{hr}$ instead of $5 \mathrm{hr}$ despite the higher adsorption at $5 \mathrm{hr}$ (see Fig. 2c), to reduce the total experimental duration. In an actual application one will also need to find an optimum between adsorption per cycle and adsorption per total time. For both ions, the measured accumulation during adsorption is very close to the release during desorption. Results are presented for two completely separate sets of experiments (crosses and triangles), with all materials replaced, and using a different ICP-OES instrument for the determination of ion concentration in the effluent. The fact that these two sets of data were very consistent, and that we closely approach "salt balance" in each data set (the same amount of ions are adsorbed as are released), suggests that the experiments are reproducible and the results reliable.

In time, the following sequence of events takes place. Firstly, directly after applying the cell voltage, both the effluent concentration of $\mathrm{Ca}^{2+}$ and of $\mathrm{Na}^{+}$decrease rapidly. As can be seen, the $\mathrm{Na}^{+}-$ concentration decreases faster than that of $\mathrm{Ca}^{2+}$, implying a higher flux of $\mathrm{Na}^{+}$into the electrodes compared to $\mathrm{Ca}^{2+}$. This is due to the initially five-times higher $\mathrm{Na}^{+}$concentration in the channel.

After this initial decrease in effluent concentration, the electrodes gradually start to saturate, leading to increasing effluent concentrations, eventually converging back to their inlet values. Remarkably, all this time, up to the end of the adsorption step, the $\mathrm{Ca}^{2+}$-concentration remains clearly below its inlet concentration of $C_{\mathrm{in}, \mathrm{Ca}}=1 \mathrm{mM}$, whereas the $\mathrm{Na}^{+}$-concentration increases to beyond its inlet concentration of $c_{\mathrm{in}, \mathrm{Na}}=5 \mathrm{mM}$ and stays above $c_{\mathrm{in}, \mathrm{Na}}$ until the end of the adsorption step, a phenomenon also observed in ref. [18]. This behavior is a clear signature of a replacement process, in which the 
composition of the EDLs, initially predominantly containing $\mathrm{Na}^{+}$, is slowly modified toward the final equilibrium composition which is dominated by $\mathrm{Ca}^{2+}$. The fact that in the end more $\mathrm{Ca}^{2+}$ is adsorbed than $\mathrm{Na}^{+}$is also evident from the effluent concentration profile during the desorption step, starting at $1 \mathrm{hr}$ in Fig. 3a, since the integrated $\mathrm{Ca}^{2+}$-peak surface area during desorption is $\sim 40 \%$ higher than the $\mathrm{Na}^{+}$release peak. Thus, the data in Fig. $3 a$ show that $\mathrm{Na}^{+}$is first adsorbed into the EDLs in the electrodes but after $\sim 10 \mathrm{~min}$ is steadily being replaced again by $\mathrm{Ca}^{2+}$. Thus the ionic flux of $\mathrm{Na}^{+}$into the electrodes is first positive and then flips sign to become negative until the end of the adsorption step, even though there is still a net driving force for ion adsorption, i.e., the cell voltage is still applied.
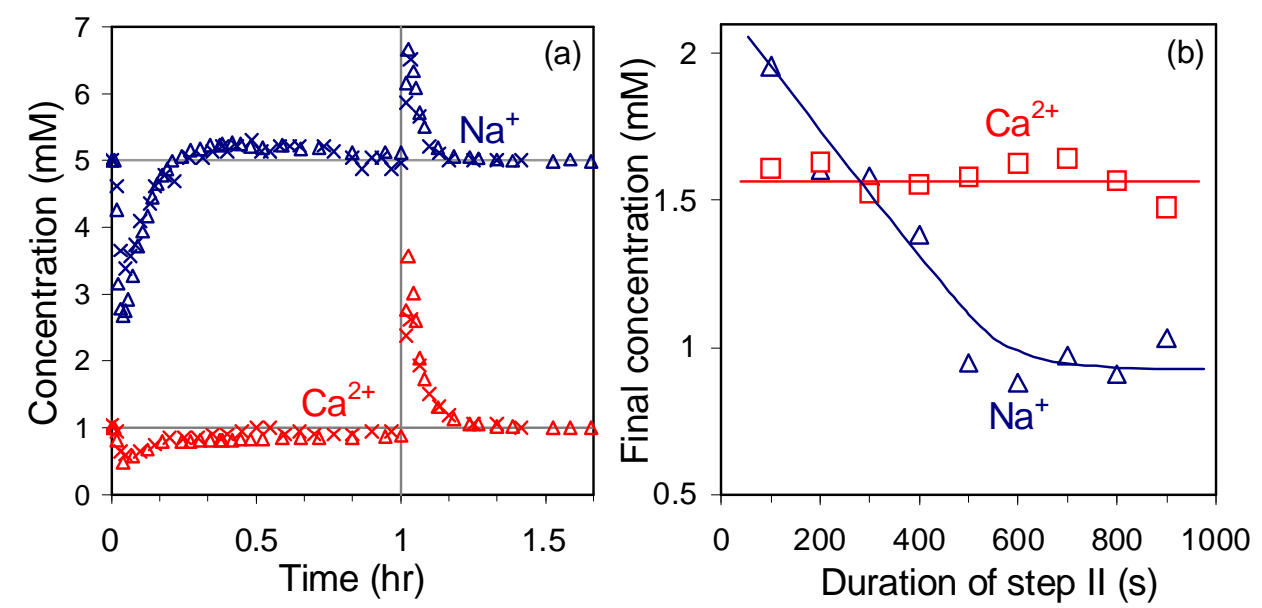

Fig. 3. Experimental data of ion-selectivity of porous electrodes in a capacitive deionization-cell, see Fig. 1. (a). Ion effluent concentration in a mixture of $\mathrm{NaCl}$ and $\mathrm{CaCl}_{2}$ during adsorption at $V_{\text {cell }}=1.2 \mathrm{~V}$, and desorption after $t=1 \mathrm{hr}$ at $V_{\text {cell }}=0 \mathrm{~V}$. (b) Final ion concentrations obtained in recycle volume in the ion recovery-step III as function of duration of washing step II. Lines serve to guide the eye.

This adsorption experiment, as reported in Fig. 3a, demonstrates that ion adsorption by porous electrodes from mixed electrolytes can change from mainly monovalent ion adsorption in the EDLs (when the monovalent ion is also the majority ion, i.e., with higher inflow concentration) to a situation where we have mainly divalent ion adsorption in the EDLs, which requires enough time for ion adsorption to proceed. The preference of the electrodes toward divalent ions, given enough adsorption time, suggests that it must also be possible to obtain an effluent enriched in these divalent ions. However, this is not yet conclusively shown solely on the basis of the adsorption experiment of Fig. 3a, and we have yet to demonstrate that it is possible to obtain a final product volume with a $\mathrm{Ca}^{2+} / \mathrm{Na}^{+}$ concentration ratio that is higher than of the starting solution. The increase of this ratio we will call the "Ca/Na-upconcentration" (UC).

To achieve this aim, the following three-step process was designed: (I) adsorption at $V_{\text {cell }}=1.2 \mathrm{~V}$ for 1 hr just as in Fig. 3a; (II) flushing, or "washing", the stack by flowing pure water to remove the salt solution from the channels and electrodes, while we use an electrically open circuit between the electrodes to trap the electrical charge in the EDLs; and (III) an ion recovery step, where by setting $V_{\text {cell }}=0 \mathrm{~V}$ (i.e., electrically short-circuiting the cell), the adsorbed ions in the electrodes are released into initially pure water, which is recycled in a closed circuit of total water volume $V=350 \mathrm{ml}$ back to the CDI-stack. 
Fig. 3b shows the final concentrations of $\mathrm{Na}^{+}$and $\mathrm{Ca}^{2+}$ in this recycle volume (at the end of step III) as function of the duration of the washing step II. As Fig. 3b shows, when the washing step II is not long enough (e.g. $100 \mathrm{~s}$ ), we do not obtain an optimal UC in the full process (end of recycle step III). However, beyond a duration for washing of $500 \mathrm{~s}$, the recycle concentrations (end of step III) are no longer a function of the duration of the washing step (step II). Fig 3b shows that recycle concentrations are much different from the initial ones, with a $6 x$ reduction in $\mathrm{NaCl}$ concentration and a $60 \%$ increase in $\mathrm{CaCl}_{2}$ concentration. This implies that we have achieved $\mathrm{UC} \sim 10$ in this three-step process. Of course it is possible to repeat this process several times, similar to using staged operation in chemical industry. Thus, we take the final ionic composition of the first run (leading to UC 10), as the feed concentration for a next run in which we perform the three-step process once again, resulting after this second run in final concentrations of $0.15 \mathrm{mM}$ for $\mathrm{Na}^{+}$and $2.1 \mathrm{mM}$ for $\mathrm{Ca}^{2+}$. Taking these concentrations one more time as the feed concentration for a third run, we obtain in the recycle volume values of $0.04 \mathrm{mM}$ and $2.3 \mathrm{mM}$ for the final concentration for $\mathrm{Na}^{+}$and $\mathrm{Ca}^{2+}$. Thus in this threerun process, an overall UC of $\sim 300$ was achieved (2.3/0.04/(1.0/5.0) 300), with the $\mathrm{Na}^{+}$-ion depleted by over a factor of 100 from the water. This admittedly is a rather circuitous experiment, but in our view it certainly has an important message, namely showing the potential of porous electrodes and electric field effects to differentially separate one ion from the other in aqueous streams of mixed ion composition without the need for special chemical treatment of the electrode or the use of ion-selective layers.

\section{Non-linear Theory - Porous Electrodes}

To describe ion adsorption in electrical double layers (EDLs), be it next to a planar electrode or inside the pores a porous electrode, linear (Debye-Hückel) theory fails even in the standard situation of a 1:1 salt solution, because it predicts that there is no net salt adsorption in the EDLs since in the linear limit the amount of counterion adsorption is exactly negatively offset by coion desorption $[48,49,51,55,56]$. Thus, in a pair of two equal electrodes electrically biased relative to one another (with one serving as anode, the other as cathode), no net salt adsorption is predicted. That desalination does occur as a matter of fact in capacitive deionization (CDI) is because conditions of non-linearity apply, where EDL-voltages are significantly above the thermal voltage unit of $R T / F \sim 25.7 \mathrm{mV}$. Therefore, to describe desalination in CDI a non-linear theory is required as we will present below. On top of that, a full non-linear process model including both electrodes that are found in the CDI cell is by necessity two-dimensional considering both the coordinate running into the electrode and the one along the electrode, from inlet to exit of the cell. However, this complete twodimensional model is not yet available.

In this work we consider a simplified geometry, with the objective to theoretically illustrate the phenomenon of time-dependent ion selectivity, and as a first step to the full two-dimensional CDI flow model. To this end, we extend non-linear theory for planar [48] and porous electrodes $[49,51,54]$ developed for $1: 1$ salt solutions, to the case of solutions containing both $\mathrm{NaCl}$ and $\mathrm{CaCl}_{2}$. We will neglect effects of surface charge in the electrode of a chemical origin, related to how far the local $\mathrm{pH}$ deviates from the point of zero charge $[54,57]$ and thus assume that the ionic charge in the diffuse part 
of the double layer is exactly compensated by electronic charge in the nearby conducting matrix (the carbon). We consider a one-dimensional geometry only (the depth direction $x$ in Fig. 1). To describe ion electrodiffusion outside the electrode, we apply the concept of a stagnant fluid film of fixed width, called the Nernst layer, or stagnant diffusion layer (SDL).

For porous electrodes, containing macropores for ion transport (and some accumulation) in equilibrium with micropores inside the activated carbon particles, where EDLs are formed, we include the Nernst-Planck flux $\left(J_{\mathrm{NP}, i}\right)$ equation in an ion mass balance, and assume electroneutrality in the macropores, $\sum_{i} z_{i} c_{m A, i}=0$, to arrive for $\mathrm{Na}^{+}$and $\mathrm{Ca}^{2+}$ at

$\frac{\partial}{\partial t}\left(p_{\mathrm{mA}} c_{\mathrm{mA}, \mathrm{i}}+p_{\mathrm{mi}} c_{\mathrm{mi}, \mathrm{i}}\right)=-\frac{\partial J_{\mathrm{NP}, \mathrm{i}}}{\partial x}, J_{\mathrm{NP}, \mathrm{i}}=-p_{\mathrm{mA}} D_{\mathrm{i}}\left(\frac{\partial c_{\mathrm{mA}, \mathrm{i}}}{\partial x}+z_{\mathrm{i}} c_{\mathrm{mA}, \mathrm{i}} \frac{\partial \phi_{\mathrm{mA}}}{\partial x}\right)$

and

$p_{\mathrm{mi}} \frac{\partial c_{\mathrm{ch}, \mathrm{mi}}}{\partial t}=-\frac{\partial J_{\text {current }}}{\partial x}, J_{\text {current }}=-p_{\mathrm{mA}} \sum_{\mathrm{i}=\mathrm{Na}, \mathrm{Ca}}\left(z_{\mathrm{i}}\left(D_{\mathrm{i}}-D_{\mathrm{Cl}}\right) \frac{\partial c_{\mathrm{mA}, \mathrm{i}}}{\partial x}+z_{\mathrm{i}} c_{\mathrm{mA}, \mathrm{i}}\left(z_{\mathrm{i}} D_{\mathrm{i}}+D_{\mathrm{Cl}}\right) \frac{\partial \phi_{\mathrm{mA}}}{\partial x}\right)$.

where $c_{\mathrm{mA}, \mathrm{i}}$ is the ion concentration in the macropores, $c_{\mathrm{mi}, \mathrm{i}}$ that in the micropores, and $p_{\mathrm{mA}}$ and $p_{\mathrm{mi}}$ are macro- and micro-porosities defined per total electrode volume. Eqs. 1 and 2 can also be used for the SDL, by setting $p_{\mathrm{mi}}=0$ and $p_{\mathrm{mA}}=1\left(D_{\mathrm{na}}=1.33, D_{\mathrm{ca}}=0.792, D_{\mathrm{cl}}=2.03 \cdot 10^{-9} \mathrm{~m}^{2} / \mathrm{s}\right)$.

To describe ion storage in the EDLs in the micropores in the carbon particles, see Fig. 1, a simple model is used assuming a common electrical potential for the entire water-filled phase in the micropores. This modified Donnan $(\mathrm{mD})$ model is a useful approximation for strong EDL overlap in thin pores $[34,51,58-60]$. In the $\mathrm{mD}$-model, the micropore concentration, $c_{\mathrm{mi}, \mathrm{i}}$, relates to that in the macropores, $c_{\mathrm{mA}, \mathrm{i}}$, according to $c_{\mathrm{mi}, \mathrm{i}}=c_{\mathrm{mA}, \mathrm{i}} \cdot \exp \left(-z_{\mathrm{i}} \cdot \Delta \phi_{\mathrm{d}}\right)$, where $\Delta \phi_{\mathrm{d}}$ is the Donnan potential drop from macropore to micropore. The micropore charge density $c_{\mathrm{ch}, \mathrm{mi}}=\sum_{\mathrm{i}} z_{\mathrm{i}} c_{\mathrm{m}, \mathrm{i}}$ relates to a Stern layer potential drop, $\Delta \phi_{\mathrm{St}}$, according to $c_{\mathrm{ch}, \mathrm{mi}} \cdot F=-V_{\mathrm{T}} \cdot \Delta \phi_{\mathrm{St}} \cdot\left(C_{\mathrm{St}, \mathrm{vol}}+\alpha \cdot c_{\mathrm{ch}, \mathrm{mi}}{ }^{2}\right)$ where $C_{\mathrm{St}, \mathrm{vol}}$ is the Stern capacity at zero charge, and where the second term describes an increase of Stern capacity with charge, which can arise from electrostatic compression of the diffuse charge in the micropore or specific adsorption of ions on the surface [61-64]. Although the Stern capacity must eventually saturate or even decrease at high voltage, as the water dipoles become strongly aligned and/or adsorbed ions become crowded [50], our parabolic charge dependence of $C_{\mathrm{St}, \mathrm{vol}}$ is a reasonable first approximation for Grahame's celebrated electrocapillary data for mercury drop electrodes [61]. Finally, the matrix (electrode) potential, $\phi_{1}$, is constant throughout the electrode, and relates locally to the potential in the macropores according to $\phi_{1}=\phi_{\mathrm{mA}}+\Delta \phi_{\mathrm{d}}+\Delta \phi_{\mathrm{St}}$. At the SDL/electrode edge we have continuity in concentration and potential, $c_{\mathrm{sd}, \mathrm{i}}=c_{\mathrm{mA}, \mathrm{i}}$ and $\phi_{\mathrm{sdl}}=\phi_{\mathrm{mA}}$, while the gradients in $\phi$ and $c$ are a factor $p_{\mathrm{mA}}$ different.

The above equations are also used to describe a pair of porous electrodes at equilibrium (equilibrium implies that all time dependencies $\partial / \partial t$ vanish), together with $V_{\text {cell }} / V_{\mathrm{T}}=\left(\Delta \phi_{\mathrm{d}}+\Delta \phi_{\mathrm{St}}\right)_{\text {an }}-\left(\Delta \phi_{\mathrm{d}}+\Delta \phi_{\mathrm{St}}\right)_{\text {cath }}$, results of which are presented in Fig. 2 as theoretical lines. Equilibrium charge $q$ is calculated from multiplying $c_{\mathrm{ch} \text {,mi }}$ with $F$, and with the ratio $p_{\mathrm{mi}} /\left(2 \cdot \rho_{\mathrm{e}}\right)$, where $\rho_{\mathrm{e}}$ is the electrode mass density. For the individual ion adsorptions, $\Gamma_{\mathrm{i}}$, we sum $c_{i, \mathrm{mi}, \mathrm{cath}}+c_{\mathrm{i}, \mathrm{mi}, \text { an }}$ and multiply with the same ratio. 


\section{Non-linear Theory - Planar Electrodes}

For planar electrodes, we use the same model for the SDL as described above for porous electrodes. For ion adsorption in quasi-equilibrium EDLs, the transient development of excess ion surface concentrations, $\gamma_{i}$, is given by the NP-flux according to $\frac{\partial \gamma_{i}}{\partial t}= \pm J_{N P, i}[48]$ to be evaluated at the SDL/electrode boundary, while for surface charge density $\sigma$ a similar balance reads $\frac{\partial \sigma}{\partial t}= \pm F \cdot J_{\text {current }}$.

For planar electrodes, one can evaluate at each moment in time the equilibrium EDL structure by numerically solving the Poisson-Boltzmann equation in one dimension across a layer of a thickness of a few times the Debye length, to arrive at values for $\sigma, \gamma_{\mathrm{Na}}$ and $\gamma_{\mathrm{Ca}}$ as function of the dimensionless diffuse layer potential $\Delta \phi_{\mathrm{d}}$. However, ideally we make use of an analytical EDL model that relates these quantities $\gamma_{\mathrm{Na}}, \gamma_{\mathrm{Ca}}$ and $\sigma$ directly to $\Delta \phi_{\mathrm{d}}$. It is well-known that such an analytical exact relation exists for the surface charge $\sigma$ in multicomponent electrolytes [65-67]. For mixtures of $\mathrm{NaCl}$ and $\mathrm{CaCl}_{2}$ this equation is

$$
\sigma^{2}=2 \varepsilon R T \sum_{i=\mathrm{Na}, \mathrm{Ca}} c_{\mathrm{i}, \infty}\left(u^{z_{i}}-1+z_{\mathrm{i}}\left(u^{-1}-1\right)\right)
$$

where $\varepsilon$ is the dielectric permittivity of the electrolyte, where $u=\exp \left(-\Delta \phi_{d}\right)$, and where $c_{i, \infty}$ is the ion concentration of $\mathrm{Na}^{+}$and $\mathrm{Ca}^{2+}$ just outside the EDL.

Apparently, it has not yet been realized that analytical solutions also exist for the excess EDLconcentrations $\gamma_{i}$ in multi-ionic solutions. For $\mathrm{NaCl} / \mathrm{CaCl}_{2}$-mixtures, we find that the general integral equation for the ion excess EDL-adsorption near a planar electrode (Eq. 6 in [66] and Eq. 159 in [67]),

$\gamma_{\mathrm{i}}=\int_{0}^{\infty}\left(c_{\mathrm{i}}(x)-c_{\mathrm{i}, \infty}\right) \mathrm{d} x=\int_{0}^{\infty} c_{\mathrm{i}, \infty}\left(e^{-z_{\mathrm{i} \phi}(x)}-1\right) \mathrm{d} x$,

can be integrated after implementation in Eq. 4 of Gauss' law, $\sigma(x)=-\varepsilon \cdot V_{\top} \cdot d \phi(x) / d x$, and Eq. 3 using $\sigma=\sigma(x)$ and $u=\exp (-\phi(x))$, to arrive at the following exact analytical expressions. For the excess $\mathrm{Na}$-ion adsorption we obtain

$\gamma_{\mathrm{Na}}=\beta_{2} \cdot \beta_{1}^{-\frac{1}{2}} \ln \frac{1+2 \beta_{1}(u+1)+2 \sqrt{u \beta_{1}} \sqrt{(u+2) \beta_{1}+1}}{1+4 \beta_{1}+2 \sqrt{\beta_{1}} \sqrt{3 \beta_{1}+1}}$,

while for the excess Ca-ion adsorption we arrive at

$\gamma_{\mathrm{Ca}}=\beta_{2}\left(\sqrt{u} \sqrt{(u+2) \beta_{1}+1}-\sqrt{3 \beta_{1}+1}\right)-\frac{1}{2} \gamma_{\mathrm{Na}}$

where the ratio of ion concentrations outside the EDL is given by $\beta_{1}=c_{\mathrm{Ca}, \infty} / c_{\mathrm{Na}, \infty}$, and $\beta_{2}=\sqrt{\varepsilon V_{\mathrm{T}} C_{\mathrm{Na}, \infty} /(2 F)}$. Without $\mathrm{Ca}^{2+}$, Eq. 5 simplifies to the classical expressions for the $1: 1$ salt GouyChapman model, e.g., Eq. 72 in [61] and Eq. 150 in [67], while Eq. 6 simplifies to Eq. 36 in [65] and Eq. 156 in [67] when $\mathrm{Na}^{+}$is absent. These surprisingly simple formulae for multi-ion adsorption should find many applications in electrochemical physics, but here we limit application to CDI in ionic mixtures. 

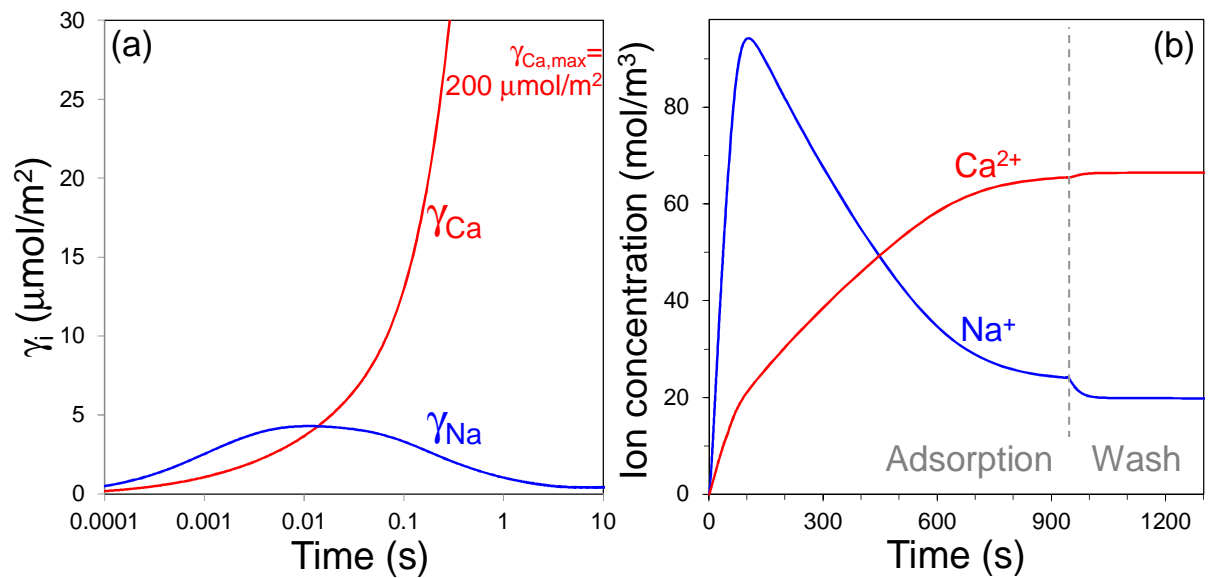

Fig. 4. Model results for ion adsorption in/at the cathode, from $5 \mathrm{mM} \mathrm{NaCl} / 1 \mathrm{mM} \mathrm{CaCl} \mathrm{C}_{2}$ mixed solutions $\left(L_{\text {sdl }}=100 \mu \mathrm{m}\right)$. (a). Excess EDL surface adsorptions for a planar electrode biased $V_{1}=-256 \mathrm{mV}$ negative to bulk solution from time zero onward. (b). Volume-averaged excess ion concentration in a porous electrode of thickness $L_{\text {elec }}=50 \mu \mathrm{m}, V_{1}(t>0)=-400 \mathrm{mV}$. From $t=940 \mathrm{~s}$ onward, open circuitconditions apply while bulk ion concentrations (outside the SDL) are reduced a factor of 1000 , in order to simulate the washing step.

\section{Discussion of Non-linear Theory}

Results of time-dependent calculations using the two models are presented in Fig. 4. Note that here results are shown of one electrode only, namely the cathode, which is the electrode onto/into which $\mathrm{Na}^{+}$and $\mathrm{Ca}^{2+}$ adsorb. Thus, these calculations must be considered as qualitative, aimed at showing the main features of the two modeling approaches. A full CDI model should not just consider the cathode but also include the anode, which in the present case with mixtures of ions of different valencies cannot be assumed to be symmetric to the cathode. Note that the theoretical results in Fig. 2 do consider both electrodes when calculating the equilibrium ion adsorption and charge according to the $\mathrm{mD}$ model.

As Fig. 4 shows, both the planar electrode model (Fig. 4a), and the porous electrode model (Fig. 4b) show that time-dependent ion-selectivity can be described by classical Nernst-Planck/EDL theory applied to mixtures of salts. For planar electrodes, the $\mathrm{Na}^{+}$-ion is only temporarily adsorbed, and almost completely desorbed again within $1 \mathrm{~s}$, while $\mathrm{Ca}^{2+}$-adsorption continues for $\sim 10 \mathrm{~s}$. This is not the behavior as we experimentally observe in Fig. 3a. The porous electrode model seems closer to reality, with a typical time scale for the reversal of ionic composition of the order of $100 \mathrm{~s}$, and with ultimately about 2.5x more $\mathrm{Ca}^{2+}$ adsorbed than $\mathrm{Na}^{+}$. This model seems to be a good starting point to develop an exact two-dimensional CDI model for mixtures, including also the Stern layer, which is not yet considered in the theoretical calculations of Fig. 4. In Fig. 4b, the ionic composition of the electrode is predicted to vary from $\mathrm{Ca}^{2+} / \mathrm{Na}^{+} \sim 0.2$ (around $100 \mathrm{~s}$ ) to $\sim 3$ (>800 s). In all of these calculations we observe that the flux of $\mathrm{Ca}^{2+}$ remains directed into the electrode at all times with a slowly decaying magnitude, while the flux of $\mathrm{Na}^{+}$starts off high and drops dramatically to become negative, which indicates the adsorption-desorption reversal.

The right half of Fig. $4 \mathrm{~b}$ shows the simulated effect of the washing step on the EDL composition. During washing with fresh water, we use an open electrical circuit and trap the charge, i.e. $J_{\text {current }}=0$, while in the experiment we flush the cell with freshwater. To simulate the wash step in the calculations, 
we suddenly reduce the bulk ion concentration outside the SDL by a factor of 1000 , and follow the response of the electrode ion concentrations in time. These calculations suggest that during the washing step II some $\mathrm{Na}^{+}$will desorb from the EDLs but the $\mathrm{Ca}^{2+}$-concentration is slightly increased, thereby obtaining an improved $\mathrm{Ca}^{2+} / \mathrm{Na}^{+}$-separation in a selective desalination process using porous electrodes.

To summarize, our theoretical analysis illustrates how time-dependent differences and sign changes in ion adsorption and desorption fluxes in charged porous electrodes are possible in ternary salt mixtures, based on an interplay of transport processes in the spacer channel and macropores, combined with differential selectivity effects in the EDLs in the carbon micropores. The complex interplay of these parameters may also explain the contradictory results on ion selectivity in the CDI literature $[10,12,13,14,18]$. To analyze these experiments in detail a full two-dimensional dynamic multicomponent CDI model is required including also proton transport $[9,68]$ and the $\mathrm{pH}$ dependence of the ionic composition in those cases that amphoteric ions such as bicarbonate anions were used. Such a model is not yet available. Other effects due to thermodynamic non-idealities in concentrated solutions and at high voltages $[52,69]$ could also lead to time-dependent selectivity based on different ion sizes and polarizabilities, and should also be analyzed. Finally, we would like to stress that the phenomenon of time-dependent ion selectivity of electrical double layers may also be important for other applications than water desalination, such as in electrophysiology [70], where the nonlinear dynamics of $\mathrm{Ca}^{2+}, \mathrm{K}^{+}$, and $\mathrm{Na}^{+}$adsorption from a majority $\mathrm{NaCl}$ solution plays a crucial role in nerve impulse propagation.

\section{Conclusions}

In this work we have shown both experimentally and theoretically that electrical double layers may adsorb and reject different ions at different times during capacitive charging of porous electrodes. Thus, capacitive cells constructed of porous electrodes can be used to selectively desalinate water by purely electrostatic means, without employing chemical absorbents or membranes. Using such a cell device, we are able to increase the $\mathrm{Ca}^{2+} / \mathrm{Na}^{+}$concentration in a product water stream by a factor of $\sim 300$ in a three-run process. Theoretical modeling based on non-linear theory for transport and capacitive charging in multi-ionic solutions predicts that when monovalent ions are present in higher concentrations than divalent ions, and for sufficiently high applied voltages, the monovalent ions are first adsorbed preferentially in the counterelectrode but later on are replaced by divalent ions.

\section{Acknowledgments}

This work was performed in the TTIW-cooperation framework of Wetsus, Centre of Excellence for Sustainable Water Technology (www.wetsus.nl). Wetsus is funded by the Dutch Ministry of Economic Affairs, the European Union Regional Development Fund, the Province of Friesland, the City of Leeuwarden and the EZ/Kompas program of the "Samenwerkingsverband Noord-Nederland." We thank the participants of the theme "Capacitive Deionization" for their involvement in this research.

*electronic address: maarten.biesheuvel@wur.nl. 


\section{References}

1. M. Hightower and S.A. Pierce, Nature 452285 (2008).

2. M.A. Shannon, P.W. Bohn, M. Elimelech, J.G. Georgiadis, B.J. Mariñas, and A.M. Mayes, Nature 452301 (2008).

3. R. Semiat, Env. Sci. Techn. 428193 (2008).

4. L.F. Greenlee, D.F. Lawler, B.D. Freeman, B. Marrot, and P. Moulin, Water Research 432317 (2009).

5. J. Biener, M. Stadermann, M. Suss, M.A. Worsley, M.M. Biener, K.A. Rose, and Th.F. Baumann, Energy \& Env. Sci. 4656 (2011).

6. M. Elimelech and W.A. Phillip, Science 333712 (2011).

7. A. Bajpayee, T. Luo, A. Muto, and G. Chen, Energy Environ. Sci. 41672 (2011).

8. H. Strathmann, Desalination 264268 (2010).

9. M.B. Andersen, M. van Soestbergen, A. Mani, H. Bruus, P.M. Biesheuvel, and M.Z. Bazant, http://arxiv.org/abs/1202.6448.

10. A.M. Johnson and J. Newman, J. Electrochem. Soc. 118510 (1971).

11. J.C. Farmer, D.V. Fix, G.V. Mack, R.W. Pekala, and J.F. Poco, J. Electrochem. Soc. 143159 (1996).

12. C.J. Gabelich, T.D. Tran, and I.H. Mel Suffet, Environm. Sci. Techn. 363010 (2002).

13. P. Xu, J.E. Drewes, D. Heil, and G. Wang, Water Research 422605 (2008).

14. C.H. Hou, P. Taboada-Serrano, S. Yiacoumi, and C. Tsouris, J. Chem. Phys. 129224703 (2008).

15. E. Avraham, B. Yaniv, A. Soffer, and D. Aurbach, J. Phys. Chem. C 1127385 (2008).

16. P.M. Biesheuvel, J. Colloid Interface Sci. 332258 (2009).

17. P.M. Biesheuvel, B. van Limpt, and A. van der Wal, J. Phys. Chem. C 1135636 (2009).

18. S.-J. Seo, H. Jeon, J.K. Lee, G.-Y. Kim, D. Park, H. Nojima, J. Lee, and S.-H. Moon, Water Research 442267 (2010).

19. R. Zhao, P.M. Biesheuvel, H. Miedema, H. Bruning, and A. van der Wal, J. Phys. Chem. Lett. 1 205 (2010).

20. M.A. Anderson, A.L. Cudero, and J. Palma, Electrochimica Acta 553845 (2010).

21. T. Humplik, J Lee, S.C. O'Hern, B.A. Fellman, M.A. Baig, S.F. Hassan, M.A. Atieh, F. Rahman, T. Laoui, R. Karnik, and E.N. Wang, Nanotechnology 22292001 (2011). 
22. B.G. Jeon, H.C. No, and J.I. Lee, Desalination 274226 (2011).

23. S. Porada, L. Weinstein, R. Dash, A. van der Wal, M. Bryjak, Y. Gogotsi, and P.M. Biesheuvel, ACS Appl. Mat. \& Interf. 41194 (2012).

24. G. Wang, C. Pan, L. Wang, Q. Dong, C. Yu, Z. Zhao, and J. Qiu, Electrochimica Acta 6965 (2012).

25. S. Porada, M. Bryjak, A. van der Wal, and P.M. Biesheuvel, Electrochimica Acta, xx xxx (2012). DOI: http://dx.doi.org/10.1016/i.electacta.2012.04.083

26. C. Nie, L. Pan, H. Li, T. Chen, T. Lu, and Z. Sun, J. Electroanal. Chem. 66685 (2012).

27. M. Mossad and L. Zou, J. Hazardous Mat. 213-214 491 (2012).

28. Z.-H. Huang, M. Wang, L. Wang, and F. Kang, Langmuir 285079 (2012).

29. J.-B. Lee, K.-K. Park, H.-M. Eum, and C.-W. Lee, Desalination 196125 (2006).

30. H. Li, Y. Gao, L. Pan, Y. Zhang, Y. Chen, and Z. Sun, Water Res. 424923 (2008).

31. P.M. Biesheuvel and A. van der Wal, J. Membr. Sci. 346256 (2009).

32. Y.-J. Kim and J.-H. Choi, Water Research 44990 (2010).

33. H. Li and L. Zou, Desalination 27562 (2010).

34. P.M. Biesheuvel, R. Zhao, S. Porada, and A. van der Wal, J. Colloid Interf. Sci. 361239 (2011).

35. S.J. Kim, S.H. Ko, K.H. Kang, and J. Han, Nat. Nanotechnol. 5297 (2010).

36. M. Pasta, C.D. Wessells, Y. Cui, and F. La Mantia, Nano Lett. 12839 (2012).

37. C. Forrestal, P. Xu, and Z. Ren, Energy \& Environm. Sci. 57161 (2012).

38. S. Porada, B.B. Sales, H.V.M. Hamelers, and P.M. Biesheuvel, J. Phys. Chem. Lett. 31613 (2012).

39. H. Elderfield and M.J. Greaves, Nature 296214 (1982).

40. Y Hou, R. Vidu and P. Stroeve, Ind. Eng. Chem. Res. 508954 (2011).

41. S. Kondrat, V. Presser, C.R. Perez, Y. Gogotsi and A.A. Kornyshev, Energy Environm. Sci. 56474 (2012)

42. V.L. Shapovalov and G. Brezesinski, J. Phys. Chem. B 11010032 (2006).

43. P.M. Biesheuvel and M. van Soestbergen, J. Colloid Interface Sci. 316490 (2007).

44. E. Wernersson, R. Kjellander, and J. Lyklema, J. Phys. Chem. C 1141849 (2010).

45. I.C. Bourg and G. Sposito, J. Colloid Interface Sci. 360701 (2011).

46. W. Wang, R.Y. Park, A. Travesset, and D. Vaknin, Phys. Rev. Lett. 106056102 (2011). 
47. S.Sigalov, M.D. Levi, G. Salitra, D. Aurbach, A. Jänes, E. Lust, and I.C. Halalay, Carbon 503957 (2012).

48. M.Z. Bazant, K. Thornton, and A. Ajdari, Phys. Rev. E 70021506 (2004).

49. P.M. Biesheuvel and M.Z. Bazant. Phys. Rev. E 81031502 (2010).

50. L.H. Olesen, M.Z. Bazant, and H. Bruus, Phys. Rev. E 82011501 (2010).

51. P.M. Biesheuvel, Y. Fu, and M.Z. Bazant. Phys. Rev. E 83061507 (2011).

52. M.Z. Bazant, M.S. Kilic, B.D. Storey, and A. Ajdari, Adv. Coll. Interface Sci. 15248 (2009).

53. D. Brogioli, R. Zhao, and P.M. Biesheuvel, Energy \& Env. Science 4772 (2011).

54. P.M. Biesheuvel, Y. Fu and M.Z. Bazant, Russ. J. Electrochem, 48, 580 (2012).

55. S.Sigalov, M.D. Levi, G. Salitra, D. Aurbach, and J. Maier, Electrochem. Comm. 121718 (2010).

56. M.D. Levi, S. Sigalov, G. Salitra, D. Aurbach, and J. Maier, CHEMPHYSCHEM 12854 (2011).

57. L.-H. Shao, J. Biener, D. Kramer, R.N. Viswanath, Th.F. Baumann, A.V. Hamza, J. Weissmüller, PCCP 12, 7580 (2010).

58. G. Feng, R. Qiao, J. Huang, B.G. Sumpter, and V. Meunier, ACS Nano 42382 (2010).

59. M.A. Murad and C. Moyne, Comput. Geosci. 1247 (2008).

60. M. Muller and B. Kastening J. Electroanal. Chem. 374149 (1994).

61. D.C. Grahame, Chem. Rev. 41441 (1947).

62. J.R. Macdonald and C.A. Barlow, J. Chem. Phys. 36, 3062 (1962).

63. M.Z. Bazant, K.T. Chu, and B.J. Bayly, SIAM J. Appl. Math. 651463 (2005).

64. D.J. Bonthuis, S. Gekle, and R.R. Netz, Physical Review Letters 107, 166102 (2011).

65. D.C. Grahame, J. Chem. Phys. 211054 (1953)

66. K.M. Joshi and R. Parsons, Electrochimica Acta 4129 (1961).

67. D.M. Mohilner, The electrical double layer. Part I. Elements of double-layer theory. pp. 241-409 in Electroanalytical Chemistry 1 (1966), A.J. Bard (ed.) Dekker, NY.

68. M. van Soestbergen, A. Mavinkurve, R.T.H. Rongen, K.M.B. Jansen, L.J. Ernst, and G.Q. Zhang, Electrochimica Acta 555459 (2010).

69. P.M. Biesheuvel, J. Colloid Interface Sci. 355389 (2011).

70. T.F. Weiss. Cellular Biophysics, Vol. 2: Electrical Properties (MIT Press, 1996). 